Article

\title{
Influence of Optical Brightening Agent Concentration on Properties of Cotton Fabric Coated with Photochromic Microcapsules Using a Pad-Dry-Cure Process
}

\author{
Mateja Kert ${ }^{1, *}$, Vida Krkoč ${ }^{2}$ and Marija Gorjanc ${ }^{1}$ (D) \\ 1 Department of Textiles, Graphic Arts and Design, Faculty of Natural Sciences and Engineering, \\ University of Ljubljana, 1000 Ljubljana, Slovenia; marija.gorjanc@ntf.uni-lj.si \\ 2 Tekstina tekstilna industrija d.o.o., 5270 Ajdovščina, Slovenia; vida.krkoc@tekstina.si \\ * Correspondence: mateja.kert@ntf.uni-lj.si
}

Received: 15 October 2019; Accepted: 19 November 2019; Published: 21 November 2019

\begin{abstract}
The weak photostability of photochromic dyes applied to textile substrates is one of the disadvantages of the broader use of photochromic dyes in the textile industry. Therefore, the influence of optical brightener concentration on both the photocoloration and photostability of cotton fabric coated with photochromic microcapsules using a pad-dry-cure process, as well as the physical-mechanical properties and colorfastness properties, were studied in this research. Coated samples were subjected to different tests according to valid EN ISO standards; namely mass per unit area, fabric stiffness, breaking force and elongation, air permeability, and different colorfastness properties (rubbing, domestic and commercial laundering, and light). Results showed that the coated fabric had higher mass per unit area, stiffness, breaking force and elongation and lower air permeability compared to uncoated fabric, irrespective of the padding bath composition. Coated fabric has better colorfastness to wet than dry rubbing. The colorfastness to washing decreases with the increased number of washing cycles. The use of optical brightener decreases the photocoloration of coated fabric and increases the photostability of coated fabric after the exposure of samples to a Xenotest apparatus for longer than $12 \mathrm{~h}$.
\end{abstract}

Keywords: photochromic microcapsules; photocoloration; cotton; optical brightening agent; pad-drycure process

\section{Introduction}

Optical brighteners are generally used to raise the whiteness of chemically bleached textile substrates. They are fluorescent chemicals that absorb in the ultraviolet (UV) region of the spectrum and emit light in the blue-violet region of the visible spectrum. The most common optical brighteners for cellulosic fibers are triazinyl derivatives of diaminostilbenedisulphonic acid with different substituents, on which substantivity and application method depends [1]. The optical brightener itself cannot change any physical-mechanical properties of fabric after application, but its working mechanism could have an influence on photochromic characteristics of photochromic dyes.

Photochromic organic compounds have an ability to transform from form A to form B and vice versa. The reversible transformation is induced in one or both directions by electromagnetic radiation between two stages possessing observable light absorptions in different regions [2]. Photochromic dyes can be applied onto textiles by exhaust dyeing, solvent-based dyeing methods, printing, or using sol-gel technology [3-18]. On glass plates, they are usually applied by sol-gel technology [19-21]. The incorporation of photochromic dye into the fiber is also established [22,23]. In general, photochromic 
dyes are poorly exhausted on textile substrates [4,6] due to their highly non-planar ring-closed form and the deficiency of substituents, which increases the solubility of the dye in an aqueous medium. Consequently, the poor photochromic color build-up is obtained on textile substrates. Furthermore, the study of the synthesis and application of water-soluble photochromic dyes, and the study of photochromic dye with a reactive anchor are already published [5,8]. Commercial photochromic dyes are often in the form of microcapsules [3], and thus they are applied onto textile substrates by pad-dry-cure processes, coating, or printing [24-26] and the photochromic color build-up is more pronounced. Moreover, plasma treatment could even increase the embedment of UV-responsive microcapsules to polyethylene terephthalate fabric during the pad-dry-cure process [27].

In ophthalmics, photochromic dyes achieved commercial success, but in the textile industry, they are rarely represented due to poor colorfastness to light and washing [3]. The other reason could lie in the non-conventional dyeing process for their application to textiles, due to the form in which commercial photochromic colorants are supplied [3]. Research carried out so far showed weak photostability of photochromic dyes applied to textiles, which can be improved by the use of UV-absorbers or hindered amine light stabilizers (HALS) [15]. From the study, researchers established that the photostability is strongly dependent on the concentration and structure of the photochromic dye, UV-absorbers, and HALS. The light fatigue resistance of spiropyranes can be also improved by the addition of nickel or zinc 4,8-dihydroxyquionline-2-carboxilated, which causes the stabilization of the dye due to the contribution of bifunctional amphoteric counterions [28]. Furthermore, studies on the influence of optical brightener concentration on the photocoloration and photostability of microencapsulated photochromic dye applied onto the cotton fabric by pad-dry-cure processes were not found. Therefore, the aim of our research was to establish if the addition of an optical brightener into the padding bath could reduce the background color and improve the photostability of the fabric coated with photoresponsive microcapsules. Thus, four different concentrations of optical brightener were used in the research. It was assumed that the addition of the optical brightener will influence both the intensity of the developed color after exposure of the coated fabric to ultraviolet A (UVA) light and the photostability of the coated fabric. Moreover, physical-mechanical characteristics of coated fabrics were also studied.

\section{Materials and Methods}

\subsection{Fabric}

Desized, scoured and chemically bleached $100 \%$ cotton fabric from the producer Tekstina Ajdovščina (plain weave, mass of $119.79 \mathrm{~g} / \mathrm{m}^{2}$, warp density 50 threads $/ \mathrm{cm}$, weft density 30 threads $/ \mathrm{cm}$ ) was used in the research.

\subsection{Chemicals}

Commercial microencapsulated photochromic dye (Itofinish UV blue, MagnaColours, Barnsley, UK), acrylic copolymer (Itobinder AG, MagnaColours, Barnsley, UK) and optical brightener (Ultraphor CK, BASF, Ludwigshafen, Germany), a derivate of stylbenedisulphonic acid, were used in the research.

\subsection{Textile Coating with Photochromic Microcapsules}

Photoresponsive microcapsules were applied onto the cotton fabric by a pad-dry-cure process. The composition of the padding baths is presented in Table 1 . The wet pick-up was $98 \%$. After padding, the cotton fabric was dried for $2 \mathrm{~min}$ at $100{ }^{\circ} \mathrm{C}$ and then cured for 4 min at $150{ }^{\circ} \mathrm{C}$. 
Table 1. Composition of the padding bath and sample labeling.

\begin{tabular}{ccccc}
\hline \multirow{2}{*}{ Sample } & \multirow{2}{*}{ Padding Bath } & \multicolumn{3}{c}{ Concentration $(\mathrm{g} / \mathrm{L})$} \\
\cline { 3 - 5 } & & Itofinish UV Blue & Itobinder AG & Ultraphor CK \\
\hline S1 & - & - & - & - \\
S2 & B1 & 100 & 50 & 0 \\
S3_1 & B2 & 100 & 50 & 0.2 \\
S3_2 & B3 & 100 & 50 & 0.4 \\
S3_3 & B4 & 100 & 50 & 0.6 \\
S3_4 & B5 & 100 & 50 & 0.8 \\
S4 & B6 & 100 & 50 & 0 \\
S5 & B7 & 0 & & 0 \\
\hline
\end{tabular}

\subsection{Methods}

\subsubsection{Mass per Unit Area}

The mass per unit area, expressed in $\mathrm{g} / \mathrm{m}^{2}$, of the studied samples was determined using the EN 12127: 1999 standard.

\subsubsection{Stiffness}

The stiffness of uncoated and coated samples was determined using method A of the ASTM D1388-64 standard. Stiffness in the warp and weft directions, expressed in $\mathrm{mg} \cdot \mathrm{cm}$, was calculated from Equation (1). Overall flexural rigidity $\left(U_{k}\right)$ was expressed from Equation (2).

$$
\begin{gathered}
U_{o, v}=T \cdot\left(\frac{\bar{l}_{o, v}}{2}\right)^{3} \\
U_{k}=\sqrt{U_{0} \cdot U_{v}}
\end{gathered}
$$

where $T$ is the mass per unit area in $\mathrm{g} / \mathrm{m}^{2}$, and $\bar{l}$ is an average value of bending length in warp $(o)$ or weft $(v)$ direction in $\mathrm{cm}$.

\subsubsection{Breaking Force and Elongation}

The tensile rigidity of the fabric was determined using the EN ISO 13934-1: 1994 standard. Some modification of the standard was performed. Namely, from each studied sample, five test pieces in the warp and five test pieces in the weft direction were cut out, with dimensions of $150 \mathrm{~mm} \times 25 \mathrm{~mm}$. Each test piece was subjected to tensile loading by an Instron 5567 dynamometer (Instron, Buckinghamshire, UK) with a fasten length of $50 \mathrm{~mm}$ and a velocity load of $100 \mathrm{~mm} / \mathrm{min}$.

\subsubsection{Air Permeability of the Textile}

The air permeability of the uncoated and coated samples was analyzed by an Air-Tronic 3240B apparatus (Mesdan, Brescia, Italy), using the ISO 9237: 1995 standard. On each sample, 10 measurements were done at a pressure of $500 \pm 2 \mathrm{~Pa}$, with a testing area of $100 \mathrm{~cm}^{2}$.

\subsubsection{Spectrophotometric Measurements}

The color of coated samples was analyzed using a Datacolor SF 600 PLUS-CT spectrophotometer (Lawrenceville, NJ, USA). Reflectance $(R)$ and CIELAB color coordinates were determined before and after the irradiation of coated samples to UVA light for $1 \mathrm{~min}$ using two Philips TL-D 18W actinic bulbs. The distance between the bulbs and the sample was $11 \mathrm{~cm}$. All measurements were performed using four layers of fabric with a $9 \mathrm{~mm}$ aperture, with specular reflectance included and the UV component excluded ( $0 \% \mathrm{UV}$, filter FL40 on), under $\mathrm{D}_{65}$ illumination and with a $10^{\circ}$ standard observer. An average 
of five measurements were taken for each sample. Due to dynamic color change, which is specific for photochromic dyes, the colorfastness properties of coated samples were evaluated from the values of color difference $\left(\Delta E_{a b}^{*}\right)[13,15]$, calculated between tested (colorfastness to rubbing, laundering and light) samples before and after irradiation with UVA light for $1 \mathrm{~min}$ and compared to those before testing.

\subsubsection{Colorfastness to Rubbing}

The testing of the colorfastness of coated samples to rubbing was performed on a Crockmeter M238BB (SDL ATLAS, Rock Hill, SC, USA) using the EN ISO 105-X12: 2002 standard.

\subsubsection{Colorfastness to Domestic and Commercial Laundering}

The colorfastness to domestic and commercial laundering was performed according to the EN ISO 105-C06: 2012 standard. Washing was performed in a GyroWash apparatus (James Heal, Halifax, UK) using test methods A1S and A1M. European Colourfastness Establishment (ECE) detergent without a fluorescent whitening agent was used as a washing agent. According to the standard, the results of one multiple (M) test may in some cases be approximated by the results of up to five domestic or commercial launderings at temperatures not exceeding $70^{\circ} \mathrm{C}$. Thus, the test method A1M was performed twice, corresponding to 10 washing cycles.

\subsubsection{Colorfastness to Light}

Studied samples were exposed to a xenon arc lamp for 1, 6, 12, and $24 \mathrm{~h}$ in a Xenotest Alpha apparatus (Atlas, Rancho Cucamonga, CA, USA). Samples were prepared according to EN ISO 105-B02:2014 standard and subjected to testing.

\subsubsection{Scanning Electron Microscopy (SEM)}

SEM JSM-6060LV (JEOL, Tokyo, Japan) was used to take SEM micrographs of S2 and S3_4 samples before and after dry and wet rubbing at $200 \times$ magnification. The average diameter of microcapsules was $5.59 \mu \mathrm{m}$, with a standard deviation of $1.60 \mu \mathrm{m}$. Measurements of microcapsule diameter, taken from SEM micrographs at 700× magnification, were determined on 50 microcapsules.

\section{Results and Discussion}

\subsection{Physical-Mechanical Properties of Samples}

\subsubsection{Mass per Unit Area}

The coated samples had a higher mass per unit area than uncoated ones (Table 2), which is expected. From the values of T, (samples S3_1-S3_4) it can be seen that the concentration of optical brightener $(\mathrm{OB})$ influences the values of $T$. With the increase in the concentration of $\mathrm{OB}$ in the padding bath (samples S3_1-S3_4), a decrease in $T$ is noticed. One of the possible explanations could be the increase in the negative charge on fiber surface due to the adsorption of $\mathrm{OB}$, containing $\mathrm{SO}_{3}{ }^{-}$groups that can repulse the application of the anionic binder into which photochromic microcapsules are entrapped. This was confirmed by SEM micrographs of samples S2 and S3_4 (Figure 1). They showed that sample S3_4, whose padding bath includes the highest amount of $\mathrm{OB}$, contains a lower number of microcapsules compared to sample $\mathrm{S} 2$, which was padded without OB.

\subsubsection{Stiffness}

All samples had higher flexural rigidity in the warp than in the weft direction (Table 2), which is in accordance with the constructional parameters of the fabric. The fabric has a higher density in the warp than in the weft direction. Coated samples had higher stiffness in both directions warp and weft than the uncoated samples, which is in line with our expectations. During the curing process, the binder forms a binder layer between cotton fibers into which microcapsules are entrapped, which 
could cause the increase of fabric stiffness. Even though the values of $U_{K}$ differ among samples S3, the fluctuation of values could be ascribed to binder layer and entrapped microcapsules rather than the concentration of $\mathrm{OB}$.

Table 2. Mass per unit area $(T)$, stiffness in the warp $\left(U_{0}\right)$ and weft $\left(U_{v}\right)$ directions, overall flexural rigidity $\left(U_{k}\right)$, breaking force $\left(F_{p r}\right)$ and breaking elongation $\left(\epsilon_{p r}\right)$ in the warp and weft directions of the studied samples.

\begin{tabular}{|c|c|c|c|c|c|c|c|c|}
\hline \multirow{2}{*}{ Sample } & \multirow{2}{*}{$T\left[\mathrm{~g} / \mathrm{m}^{2}\right]$} & \multirow{2}{*}{$\begin{array}{c}U_{o} \\
{[\mathrm{mg} \cdot \mathrm{cm}]}\end{array}$} & \multirow{2}{*}{$\begin{array}{c}U_{v} \\
{[\mathrm{mg} \cdot \mathrm{cm}]}\end{array}$} & \multirow{2}{*}{$\begin{array}{c}U_{k} \\
{[\mathrm{mg} \cdot \mathrm{cm}]}\end{array}$} & \multicolumn{2}{|c|}{$F_{p r}[\mathrm{~N}]$} & \multicolumn{2}{|c|}{$\epsilon_{p r}[\%]$} \\
\hline & & & & & Warp & Weft & Warp & Weft \\
\hline S1 & 119.79 & 307.53 & 110.94 & 184.71 & 302.44 & 216.10 & 13.23 & 16.70 \\
\hline S2 & 131.49 & 430.54 & 205.30 & 297.30 & 380.31 & 235.46 & 19.33 & 17.47 \\
\hline S3_1 & 131.78 & 431.82 & 171.02 & 271.75 & 326.29 & 226.41 & 18.60 & 20.93 \\
\hline S3_2 & 131.63 & 451.86 & 218.26 & 314.04 & 371.46 & 224.18 & 19.83 & 15.97 \\
\hline S3_3 & 129.16 & 443.38 & 178.55 & 281.36 & 342.36 & 212.24 & 17.80 & 18.60 \\
\hline S3_4 & 127.94 & 439.19 & 188.15 & 287.46 & 357.23 & 244.33 & 18.87 & 18.00 \\
\hline
\end{tabular}

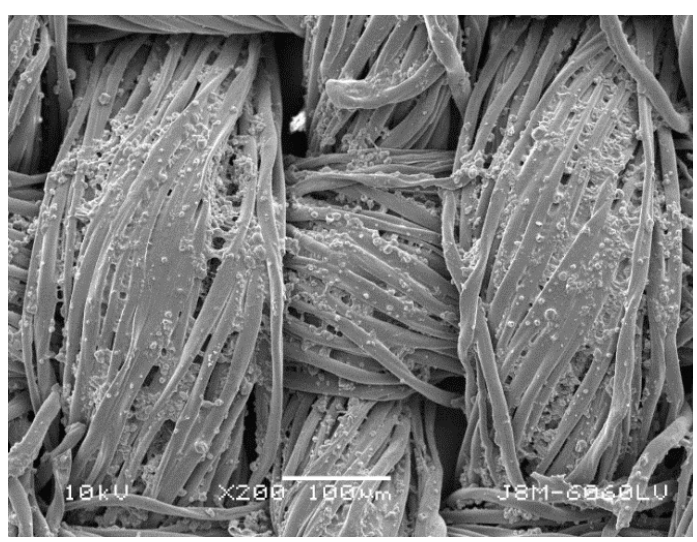

(a)

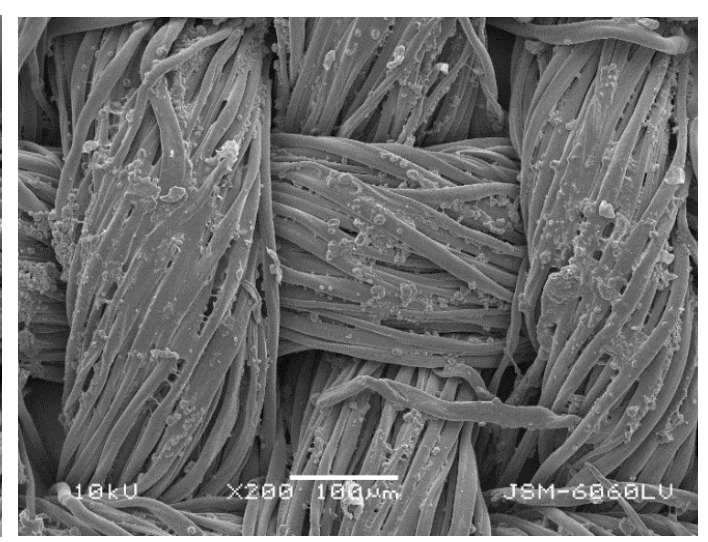

(b)

Figure 1. SEM (scanning electron microscope) micrographs of samples S2 (a) and S3_4 (b) at 200× magnification.

\subsubsection{Breaking Force and Elongation}

From the results, collected in Table 2, it can be seen that the breaking force $\left(F_{p \mathrm{r}}\right)$ of the fabric increases after the pad-dry-cure process. One of the possible reasons could be that the binder forms a binder layer during the curing process and thus fills the voids between fibers. Fibers within yarns become stronger and therefore a higher force is needed at the break. On the other hand, no deterioration of elongation at break $\left(\epsilon_{p r}\right)$ is noticed for coated samples, and it even improves slightly. A possible explanation for such a phenomenon could be that the binder layer slightly increases the elasticity of the coated fabric. Moreover, it should be stressed that the size of the test piece was $150 \times 25 \mathrm{~mm}$ and the fasten length was $50 \mathrm{~mm}$, which could also contribute to the obtained results. With the increase in $\mathrm{OB}$ concentration in the padding bath, no proportional increase or decrease in the values of $F_{p r}$ and $\epsilon_{p r}$ is noticed, which clearly shows that the OB has no influence on breaking force and elongation of coated fabric.

\subsubsection{Air Permeability}

Results in Table 3 show that the uncoated sample (S1) has essentially higher air permeability than coated samples. The lowest air permeability is shown by sample S2, padded in a bath containing photoresponsive microcapsules and binder, whilst the highest air permeability is noticed in sample S5, padded with binder only. The latter result suggests that the binder does not form a continuous layer on the fabric surface after curing and also does not close the pores between the warp and weft threads, and therefore the fabric remains sufficiently permeable for air. On the other hand, microcapsules can form 
a uniform, thin and continuous coating on the fabric surface and thus fix the spaces in the fibers [25]. The reduction of air permeability of sample $\mathrm{S} 2$ is therefore attributed to the synergistic effect of both ingredients in the padding bath, i.e., binder and microcapsules. It can also be seen from Table 3 that the air permeability of the fabric increases with the increase in $\mathrm{OB}$ concentration in the padding bath. This is additional evidence that the addition of $\mathrm{OB}$ into the padding bath reduces the adhesion between fiber and binder, and therefore a lower number of microcapsules is entrapped into the cured binder layer. The latter result is shown by SEM micrographs of samples S2 and S3_4, presented in Figure 1.

Table 3. Average values of airflow through the fabric $(\bar{q})$ and air permeability $(R)$ of the studied samples.

\begin{tabular}{ccc}
\hline Sample & $\bar{q}\left[\mathbf{d m}^{3} / \mathbf{m i n}\right]$ & $\boldsymbol{R}[\mathbf{m m} / \mathbf{s}]$ \\
\hline S1 & 91.0 & 303.8 \\
S2 & 53.1 & 177.3 \\
S3_1 & 53.6 & 179.0 \\
S3_2 & 53.7 & 179.2 \\
S3_3 & 68.3 & 228.1 \\
S3_4 & 71.8 & 239.7 \\
S4 & 52.6 & 175.7 \\
S5 & 78.2 & 261.2 \\
\hline
\end{tabular}

\subsection{Reflectance, Color and Colorfastness Properties of Tested Samples}

\subsubsection{Reflectance}

From reflectance curves of coated samples before irradiation with UVA light, presented in Figure 2, it can be seen that the addition of OB (samples S3_1-S3_4) increases reflectance values of coated samples in the studied range of wavelengths in comparison with sample S2. The reflectance slightly increases by the increase of $\mathrm{OB}$ concentration. After irradiation of the coated samples with UVA light, the decrease of reflectance is noticed, irrespective of the addition of $\mathrm{OB}$, due to the transformation of photochromic dye from colorless to colored form under UVA light. The influence of OB concentration on reflectance values is more pronounced for irradiated samples. The reflectance increases by the increase in $\mathrm{OB}$ concentration in the padding bath since OB and photochromic dye absorb UV light simultaneously. The wavelength of absorption maximum $\left(\lambda_{\max }\right)$ of studied encapsulated photochromic dye on cotton fabric is $610 \mathrm{~nm}$. The addition of OB has no influence on $\lambda_{\max }$ of the studied dye.

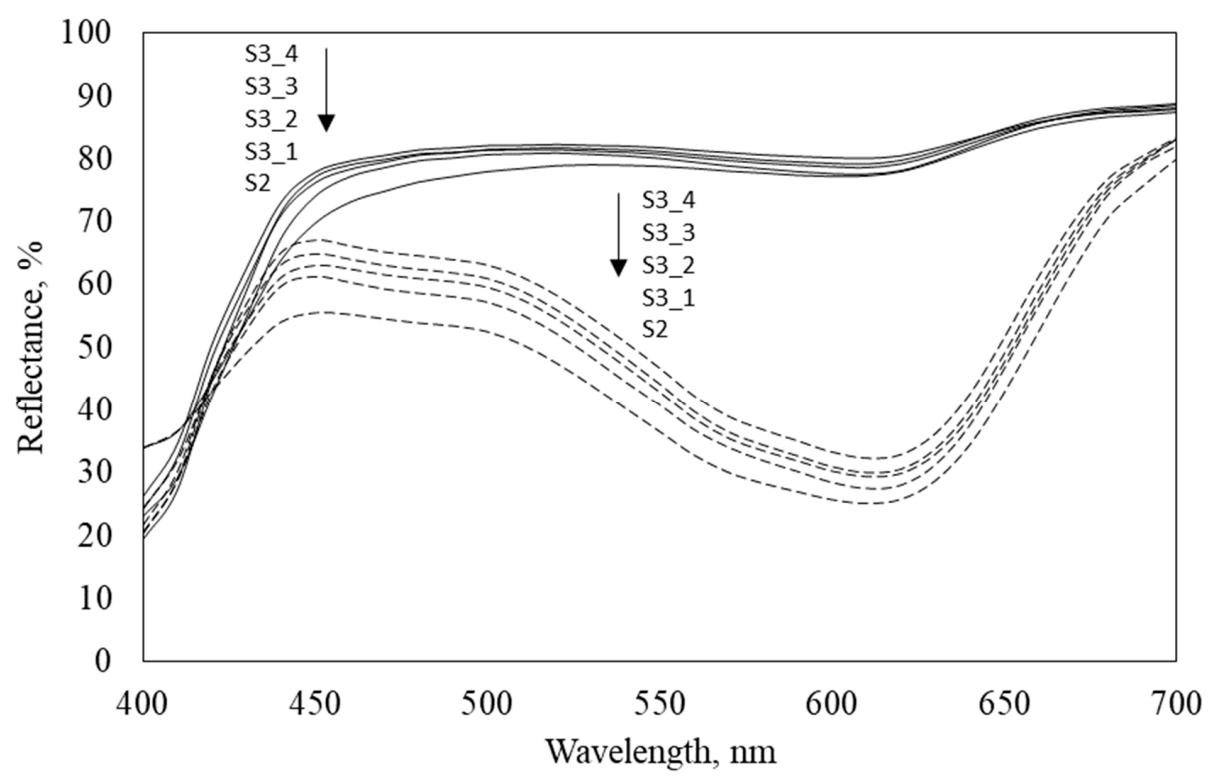

Figure 2. Reflectance curves of coated samples before (-) and after (- -) irradiation with UVA light. 


\subsubsection{Color of Tested Samples}

From CIELAB values of uncoated and coated cotton fabric (Table 4), it can be seen that the coated cotton fabric becomes darker (value of CIE $\mathrm{L}^{*}$ decreases), greener (value of CIE $\mathrm{a}^{*}$ decreases), and yellower (value of CIE $b^{*}$ increases) after the application of photochromic microcapsules. Moreover, the application of photochromic microcapsules affects the background color of the coated cotton fabric. When OB was added into the padding bath, the cotton fabric became slightly lighter, less green, and less blue. After the exposure of the coated fabric to UVA light for $1 \mathrm{~min}$ (Table 5), the fabric becomes even darker, greener (value of CIE $\mathrm{a}^{*}$ decreases), and bluer (value of CIE $\mathrm{b}^{*}$ decreases). With the increase in OB concentration in the padding bath, samples from S3_1 to S3_4 become lighter and less blue, whilst its influence on the value of CIE $\mathrm{a}^{*}$ is less perceptible.

Table 4. The CIELAB color values, chroma $\left(\mathrm{C}^{*} \mathrm{ab}\right)$ and hue $\left(\mathrm{h}_{\mathrm{ab}}\right)$ of uncoated and coated samples before exposure to UVA light.

\begin{tabular}{cccccc}
\hline Sample & $\mathbf{L}^{*}$ & $\mathbf{a}^{*}$ & $\mathbf{b}^{*}$ & $\mathbf{C}_{\mathbf{a b}}^{*}$ & $\mathbf{h}_{\mathbf{a b}}\left(^{\circ}\right)$ \\
\hline S1 & 94.21 & -0.33 & 3.17 & 3.19 & 95.96 \\
S2 & 91.60 & -5.24 & 8.37 & 9.87 & 122.08 \\
S3_1 & 91.96 & -5.43 & 7.64 & 9.37 & 125.40 \\
S3_2 & 91.83 & -5.26 & 7.16 & 8.89 & 126.31 \\
S3_3 & 92.26 & -4.81 & 6.40 & 8.01 & 126.89 \\
S3_4 & 92.24 & -4.97 & 6.63 & 8.29 & 126.85 \\
\hline
\end{tabular}

Table 5. The CIELAB color values, chroma $\left(\mathrm{C}^{*} \mathrm{ab}\right)$ and hue $\left(\mathrm{h}_{\mathrm{ab}}\right)$ of coated samples after exposure for 1 min to UVA light.

\begin{tabular}{cccccc}
\hline Sample & $\mathbf{L}^{*}$ & $\mathbf{a}^{*}$ & $\mathbf{b}^{*}$ & $\mathbf{C}_{\mathbf{a b}}^{*}$ & $\mathbf{h}_{\mathbf{a b}}\left(^{(}\right)$ \\
\hline S2 & 71.41 & -11.76 & -15.31 & 19.31 & 232.49 \\
S3_1 & 72.73 & -12.63 & -15.32 & 19.86 & 230.47 \\
S4_2 & 74.33 & -11.93 & -14.25 & 18.59 & 230.05 \\
S5_3 & 76.13 & -11.82 & -13.07 & 17.62 & 227.84 \\
S3_4 & 77.28 & -11.90 & -12.39 & 17.19 & 226.13 \\
\hline
\end{tabular}

\subsubsection{Colorfastness to Rubbing}

The values of $\Delta E_{a b}^{*}$ in Table 6 show that rubbed samples had lower $\Delta E_{a b}^{*}$ than unrubbed samples. The decrease in $\Delta E_{a b}^{*}$ is a consequence of the removal of the cured binder layer into which microcapsules are entrapped. Since the used microcapsules had no affinity to cellulosic fiber, the adhesion between microcapsules and fibers is dependent upon the binder, present in the padding bath. It can be concluded that only microcapsules were removed during rubbing, which were more present on the fabric surface than microcapsules entrapped in the cured binder layer among threads of fabric. The values of $\Delta E_{a b}^{*}$ show that the colorfastness of coated samples to rubbing is slightly influenced by the type of rubbing. With wet rubbing, higher values of $\Delta E_{a b}^{*}$ were obtained compared to dry rubbing. The cause for the removal of the cured binder layer into which microcapsules were entrapped at dry rubbing was ascribed to higher friction between the coated fabric and dry cotton fabric in comparison to wet rubbing, where coated fabric is rubbed with wet cotton fabric [26], which was confirmed by SEM micrographs of samples S2 and S3_4 (Figure 3a-d), showing that the cured binder layer into which microcapsules were entrapped was removed to a greater extent from the upper than from the lower threads and from the surface, which was more exposed to rubbing. The same observation was noticed in our previous study [26]. The lower values of $\Delta E_{a b}^{*}$ of unrubbed samples S3_1-S3_4 compared to unrubbed sample S2, were ascribed to a lower application of binder into which microcapsules were entrapped due to the presence of $\mathrm{OB}$ in the padding bath on one hand, whilst on the other hand the optical brightener and the photochromic dye absorb UV-light at the same time, resulting in a lower photocoloration of the fabric. 
Table 6. Colorfastness to rubbing of studied samples.

\begin{tabular}{cccc}
\hline \multirow{2}{*}{ Sample } & \multicolumn{3}{c}{$\Delta \boldsymbol{E}_{\boldsymbol{a} \boldsymbol{b}} \mathbf{}$} \\
\cline { 2 - 4 } & Without Rubbing & Wet Rubbing & Dry Rubbing \\
\hline S2 & 31.79 & 31.55 & 31.22 \\
S3_1 & 30.80 & 28.69 & 27.88 \\
S3_2 & 28.44 & 24.69 & 24.40 \\
S3_3 & 26.24 & 24.51 & 23.38 \\
S3_4 & 25.18 & 22.98 & 21.98 \\
\hline
\end{tabular}

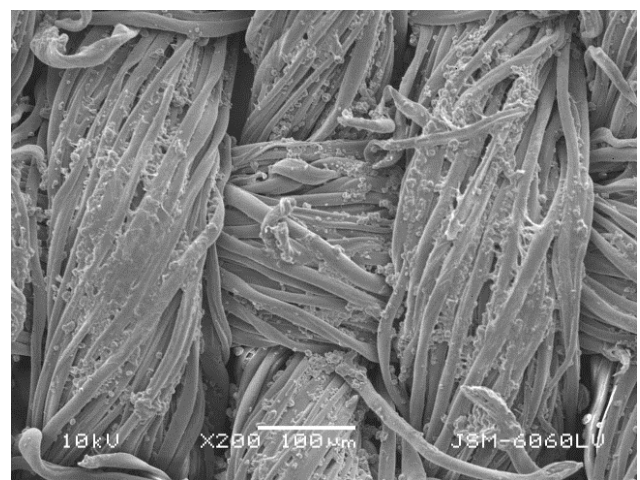

(a)

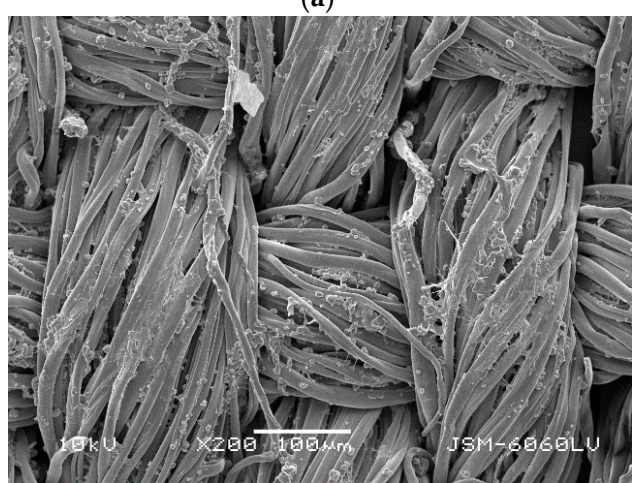

(c)

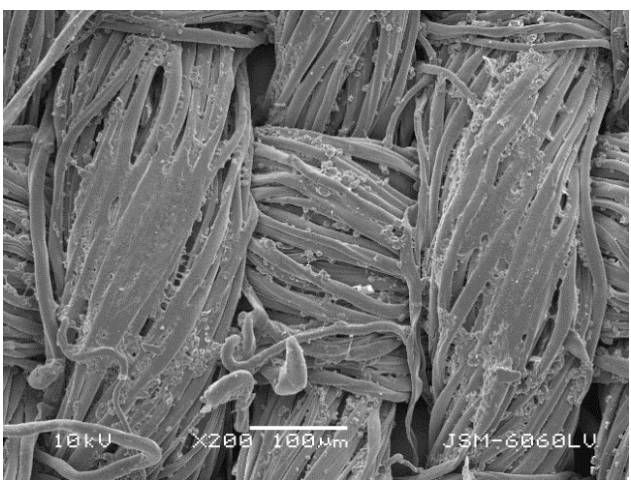

(b)

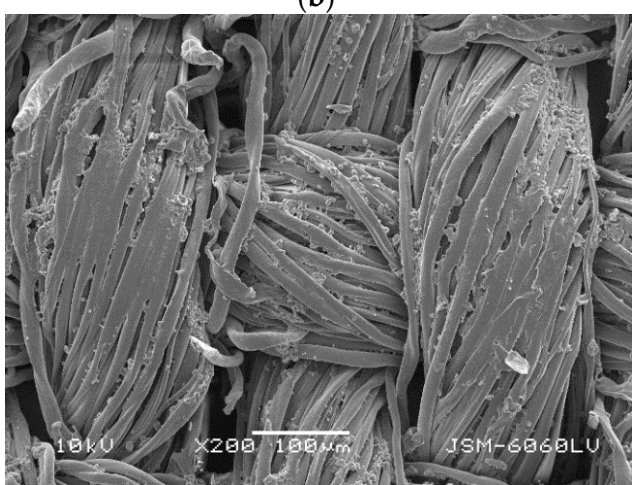

(d)

Figure 3. Sample S2 after wet (a) and dry (b) rubbing and sample S3_4 after wet (c) and dry (d) rubbing at $200 \times$ magnification.

\subsubsection{Colorfastness to Domestic and Commercial Laundering}

The values of $\Delta E_{a b}^{*}$ of washed samples decreased compared to the $\Delta E_{a b}^{*}$ of unwashed samples (Table 7), meaning that the microcapsules embedded into the binder layer were removed from the cotton fabric after the first washing cycle, whilst after 10 washing cycles an even higher decrease was noticed. It was concluded that only microcapsules that were not strongly embedded into the cured binder layer were removed during the laundering process. The results of $\Delta E_{a b}^{*}$ of samples S2 and S4 clearly show that the binder increases the adhesion between microcapsules and fiber, and therefore a higher colorfastness to laundering of sample S2 is achieved compared to sample S4. The drop in the values of $\Delta E_{a b}^{*}$ after the first and the tenth washing cycles of sample $S 4$ is higher compared to sample S2. The lower values of $\Delta E_{a b}^{*}$ of sample $S 4$ compared to sample S2 show that a lower number of microcapsules was coated onto the cotton fabric in the case of sample S4 than sample S2. The latter result is in accordance with our expectations since padding bath B6 did not include a binder as in the case of padding bath B1 (sample S2). For unwashed samples, the decrease in the value of $\Delta E_{a b}^{*}$ with the increase in $\mathrm{OB}$ concentration in the padding bath was noticed, as a consequence of lower photocoloration of samples on one hand and a lower amount of microcapsules coated on the cotton fabric on the other hand due to repulsive forces between adsorbed $\mathrm{OB}$ and the anionic binder. 
Table 7. Colorfastness to domestic and commercial laundering.

\begin{tabular}{cccc}
\hline \multirow{2}{*}{ Sample } & \multicolumn{3}{c}{$\Delta \boldsymbol{E}^{*} \boldsymbol{a} \boldsymbol{b}$} \\
\cline { 2 - 4 } & Unwashed & After One Washing Cycle & After Ten Washing Cycles \\
\hline S2 & 31.79 & 30.96 & 28.50 \\
S3_1 & 30.80 & 29.58 & 26.96 \\
S3_2 & 28.44 & 27.35 & 25.82 \\
S3_3 & 26.24 & 25.31 & 24.55 \\
S3_4 & 25.18 & 24.64 & 23.48 \\
S4 & 26.65 & 24.41 & 16.40 \\
\hline
\end{tabular}

\subsubsection{Colorfastness to Light}

After the illumination of samples in the Xenotest apparatus, the values of $\Delta E_{a b}^{*}$ of the studied samples decreased (Table 8). It is known that UV-absorbers increase the colorfastness to light of photochromic textiles [15]. Since the optical brightener absorbs UV-light, it was assumed that the addition of an optical brightener into the padding bath will improve the colorfastness to light of photochromic textiles. The latter was confirmed with the normalized degree of photostability [15] of the studied samples (Figure 4), which clearly shows that after illumination longer than $12 \mathrm{~h}$, samples from S3_1 to S3_4 have higher photostability (higher values of $\Delta E_{a b}^{*} / \Delta E_{a b}^{*}$ ) than sample S2. According to the obtained results, it can be concluded that the colorfastness of microencapsulated photochromic dye to light, applied to cotton fabric, could be improved even at low concentrations of OB. At the same time, a slight change in background color was noticed on fabric after the application of microcapsules of photochromic dye and OB.

Table 8. Color difference before $\left(\Delta E_{a b}^{*}\right)$ and after different hours $\left(\Delta E_{a b}^{*}\right)$ of illumination.

\begin{tabular}{|c|c|c|c|c|c|}
\hline \multirow{2}{*}{ Sample } & \multirow{2}{*}{$\frac{\Delta E_{a b}^{*}{ }^{o}}{0 \mathrm{~h}}$} & \multicolumn{4}{|c|}{$\Delta E_{a b}^{*}$} \\
\hline & & $1 \mathrm{~h}$ & $6 \mathrm{~h}$ & $12 \mathrm{~h}$ & $24 \mathrm{~h}$ \\
\hline S2 & 31.79 & 31.85 & 28.15 & 23.20 & 16.10 \\
\hline S3_1 & 30.80 & 28.66 & 27.19 & 24.49 & 18.32 \\
\hline S3_2 & 28.44 & 25.87 & 25.39 & 22.50 & 17.18 \\
\hline S3_3 & 26.24 & 23.93 & 23.50 & 20.00 & 16.86 \\
\hline S3_4 & 25.18 & 23.42 & 23.15 & 21.86 & 18.89 \\
\hline S4 & 26.65 & 26.64 & 26.15 & 23.53 & 17.95 \\
\hline
\end{tabular}

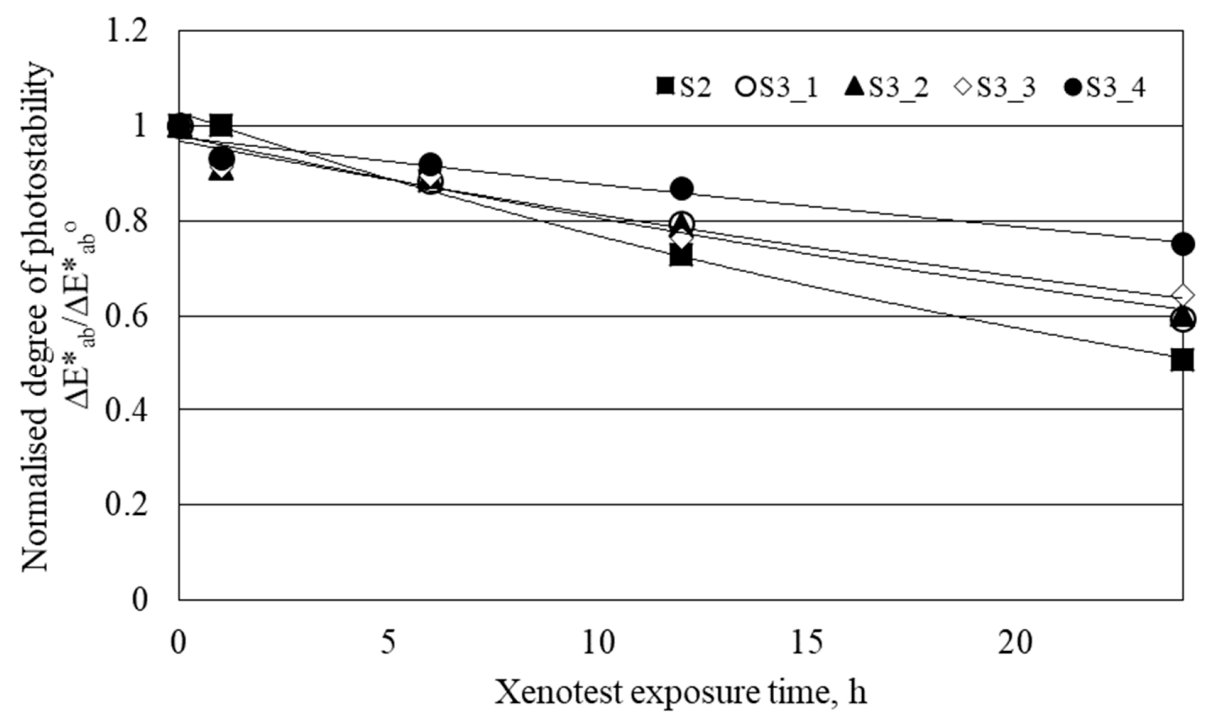

Figure 4. Normalized degree of photostability of studied samples. 


\section{Conclusions}

In this research, desized, scoured and chemically bleached cotton fabric was successfully coated with microcapsules of photochromic dye in the absence and the presence of optical brightener of different concentrations using a pad-dry-cure process. The increase of optical brightener concentration in the padding bath decreases the application of binder, into which microcapsules of photochromic dye are entrapped. After coating the flexural rigidity of the fabric increased in the warp and weft directions, irrespective of the absence or the presence of an optical brightener in the padding bath. The breaking force increased, whilst elongation of the coated fabric slightly improved. The air permeability of the coated fabric decreased, albeit to a smaller extent, when an optical brightener was present in the padding bath. The coated fabric had better colorfastness to wet than to dry rubbing, whilst the colorfastness to washing decreased with the increasing number of washing cycles. The presence of optical brightener and its concentration in the padding bath has no influence on colorfastness of coated fabric to rubbing and washing whilst its influence on light fastness is more pronounced. The colorfastness to light of the coated fabric improved with the increased concentration of optical brightener. In order to determine whether the optical brightener could be a good substitute for UV-absorbers or HALS, further research should be performed to confirm or deny this claim.

Author Contributions: Data curation, V.K.; Supervision, M.K.; Writing—original draft, M.K.; Writing—review \& editing, M.G.

Funding: This research was funded by the Slovenian Research Agency (Programme P2-0213 Textiles and Ecology).

Conflicts of Interest: The authors declare no conflicts of interest.

\section{References}

1. Shore, J. Colorants and Auxiliaries, Organic Chemistry and Application Properties, 2nd ed.; Society of Dyers and Colourists: Bradford, UK, 2002; Volume 2, pp. 761-781.

2. Crano, J.C.; Guglielmetti, R.J. Organic Photochromic and Thermochromic Compunds Main Photochromic Families; Plenum Press: New York, NY, USA, 1999; Volume 1, pp. 1-9.

3. Chowdhury, M.A.; Joshi, M.; Butola, B.S. Photochromic and Thermochromic Colorants in Textile Application. J. Eng. Fiber Fabr. 2014, 9, 107-123. [CrossRef]

4. Lee, S.-J.; Son, Y.-A.; Suh, H.-J.; Lee, D.-N.; Kim, S.-H. Preliminary exhaustion studies of spiroxazine of dye on polyamide fibers and their photochromic properties. Dyes Pigments 2006, 69, 18-21. [CrossRef]

5. Son, Y.-A.; Park, Y.-M.; Park, S.-Y.; Shin, C.-J.; Kim, S.-H. Exhaustion studies of spiroxazine dye having ractive anchor on polyamide fibers and its photochromic properties. Dyes Pigments 2007, 73, 76-80. [CrossRef]

6. Reduwan Billah, S.M.; Christie, R.M.; Shamey, R. Direct coloration of the photochromic dyes. Part 1, Application of spiroindolinonaphthoxazines as disperse dyes to polyester, nylon and acrylic fabrics. Color. Technol. 2008, 124, 223-228. [CrossRef]

7. Reduwan Billah, S.M.; Christie, R.M.; Morgan, K.M. Direct coloration of textiles with photochromic dyes. Part 2: The effect of solvents on the colour change of photochromic textiles. Color. Technol. 2008, 124, 229-233. [CrossRef]

8. Reduwan Billah, S.M.; Christie, R.M.; Shamey, R. Direct coloration of textiles with photochromic dyes. Part 3: Dyeing of wool with photochromic acid dye. Color. Technol. 2012, 128, 488-492. [CrossRef]

9. Aldib, M.; Christie, R.M. Textile applications of phtochromic dyes. Part 4: Application of commercial photchromic dyes as disperse dyes to polyester by exhaust dyeing. Color. Technol. 2011, 127, 282-287. [CrossRef]

10. Aldib, M.; Christie, R.M. Textile applications of phtochromic dyes. Part 5: Application of commercial photchromic dyes to polyester fabric by a slovent-based dyeing method. Color. Technol. 2013, 127, 131-143. [CrossRef]

11. Aldib, M. Photochromic ink formulation for digital inkjet printing and colour measurement of printed polyester fabrics. Color. Technol. 2015, 131, 172-182. [CrossRef]

12. Feczko, T.; Samu, K.; Wenzel, K.; Neral, B.; Voncina, B. Textiles screen-printed with photochromic tehyl cellulose-spirooxazine composite nanoparticles. Color. Technol. 2012, 129, 18-23. [CrossRef] 
13. Little, A.F.; Christie, R.M. Textile applications of photochromic dyes. Part 1: Establishment of a methodology for evaluation of photochromic textiles using traditional colour measurement instrumentation. Color. Technol. 2010, 127, 157-163. [CrossRef]

14. Little, A.F.; Christie, R.M. Textile applications of photochromic dyes. Part 2: Factors affecting the photocoloration of textiles screen-printed wtih commercial photochromic dyes. Color. Technol. 2010, 126, 164-170. [CrossRef]

15. Little, A.F.; Christie, R.M. Textile applications of photochromic dyes. Part 3: Factors affecting the technical performance of textiles screen-printed wtih commercial photochromic dyes. Color. Technol. 2011, 127, $275-281$. [CrossRef]

16. Reduwan Billah, S.M.; Christie, R.M.; Morgan, K.M. A Molecular Moddeling Approach Applied to a Study of the Photochromic Behaviour of Screen Printed Protein and Polyamide Substrates. Fiber Polyments 2011, 12, 701-705. [CrossRef]

17. Zhou, Y.; Yan, Y.; Du, Y.; Chen, J.; Hou, X.; Meng, J. Preparation and applicatio of melamine-formaldehyde photochromic microcapsules. Sens. Actuators B Chem. 2013, 188, 502-512. [CrossRef]

18. Chen, T.; Lin, T.; Brady, R.; Wang, X. Fast Response Photochromic Textiles from Hybrid Silica Surface Coating. Fiber Polyments 2008, 9, 301-306. [CrossRef]

19. Hou, L. Effect of Heat Treatment and additives on the Photochromic and Mechanical Properties of Sol-Gel Derived Photochromic Coatings Containing Spirooxazine. J. Sol-Gel Sci. Technol. 1997, 8, 923-926. [CrossRef]

20. Hori, T.; Tagaya, H.; Nagaoka, T.; Kaokawa, J.; Chiba, K. Photochromism of sulfonated spiropyran in a silica matrix. Appl. Surf. Sci. 1997, 121-122, 530-533. [CrossRef]

21. Hou, L. Enhancement of the Photochromic Performance of Spirooxazine in Sol-Gel Derived Organic-Inorganic Hybrid Matrices by Additives. J. Sol-Gel Sci. Technol. 1997, 8, 927-929. [CrossRef]

22. Little, A.F.; Christie, R.M. Textile applications of commercial photochromic dyes. Part 6: Photochromic polypropylene fibres. Color. Technol. 2016, 132, 304-309. [CrossRef]

23. Younes, B.; Ward, S.C.; Christie, R.M.; Vettese, S. Textile applications of commercial photochromic dyes. Part 7: A statistical investigation of the influence of photochromic dyes on the mechanical properties of thermoplastic fibres. J. Text. Inst. 2019, 110, 780-790. [CrossRef]

24. Nelson, G. Microencapsulation in textile finishing. Rev. Prog. Color. 2001, 31, 57-64. [CrossRef]

25. Fan, F.; Zhang, W.; Wang, C. Covalent bonding and photochromic properties of double-shell polyurethanechitosan microcapsules crosslinked onto cotton fabric. Cellulose 2015, 22, 1427-1438. [CrossRef]

26. Kert, M.; Gorjanc, M. The study of colour fastness of commercial microencapsulated photoresponsive dye applied on cotton, cotton/polyester and polyester fabric using pad-dry-cure process. Color. Tehnol. 2017, 133, 491-497. [CrossRef]

27. Gorjanc, M.; Mozetič, M.; Primc, G.; Vesel, A.; Spasić, K.; Puač, N.; Petrović, Z.L.; Kert, M. Plasma treated polyethylene terephthalate for increased embedment of UV-responsive microcapsules. Appl. Surf. Sci. 2017, 419, 224-234. [CrossRef]

28. Oda, H. A novel approach for improving the light fatique resistance of spiropyrans. J. Soc. Dyers Colour. 1998, 114, 363-367. [CrossRef]

(C) 2019 by the authors. Licensee MDPI, Basel, Switzerland. This article is an open access article distributed under the terms and conditions of the Creative Commons Attribution (CC BY) license (http://creativecommons.org/licenses/by/4.0/). 